\title{
Argumentation Quantity and Quality: A Litigation Success Function
}

\author{
António Osório ${ }^{\dagger}$ and Barbara Luppi ${ }^{\ddagger}$ \\ ${ }^{\dagger}$ Universitat Rovira i Virgili (Dept. of Economics) and CREIP \\ (antonio.osoriodacosta@urv.cat) \\ ${ }^{\ddagger}$ University of Modena and Reggio Emilia (Dept. of Economics).
}

\begin{abstract}
Arguments are statements used to persuade someone or in support of a claim. However, these are not perfect and the opponents can exploit them to build their own arguments. In this paper, we propose a new litigation success function that (i) considers the intrinsic and immutable strength of the arguments presented by the plaintiff and defendant, (ii) solves the limitations of the existing literature in dealing with the English fee-shifting system, and (iii) is flexible and tractable in analytical terms. As a robustness check, the proposed litigation success function confirms several important results in the literature, but also brings new insights on how argumentation strength affects the individuals' efforts and the decision to file and contest lawsuits in different fee-shifting systems. In this context, we also show how to introduce the worldwide-accepted presumption of innocence in favor of the defendant and the possibility of settlement.
\end{abstract}

Keywords:

Litigation success function, Contests success function, Argumentation strength, Fee-shifting systems.

JEL classification: C72, D72, D74, K41.

\section{Introduction}

The decision by the plaintiff to bring a case and the decision by the defendant to defend it, depend crucially on the legal system, the value under dispute, the objective merits of the case, the strength or quality of the 
arguments and the costs involved. In this process, the more resources the individuals spend to produce arguments, the more likely they are to influence the court's decision in their favor. This observation establishes a link between the litigation process and the Tullock's (1980) type "rent-seeking" literature (Katz, 1988), ${ }^{1}$ and justifies why this methodology is being extensively applied to studying legal disputes. ${ }^{2}$

However, the "rent-seeking" Contest Success Function (CSF) has a number of limitations. In particular, under the English system no case reaches trial because the intensity of argumentation is too high. The exception occurs in the very particular case in which the returns to scale in the production of legal arguments are decreasing and sufficiently low (Farmer and Pecorino, 1999). ${ }^{3}$ However, in this case, the introduction of realistic considerations, such as, for example, asymmetries between individuals, outside options or other aspects is analytically intractable (Dari-Mattiacci et al., 2015). Analytical tractability can be recovered by assuming constant returns to scale in the production of legal arguments, but then, as explained, no case reaches trial under the English system, which is counterfactual; ${ }^{4}$ thereby restricting to a great extent the generalized application of the "rent-seeking" CSF, and questioning whether this approach to litigation is complete enough. ${ }^{5}$ This

\footnotetext{
${ }^{1}$ Corchón (2007) and Konrad (2009) survey this literature in economics. In this paper, we focus on the litigation use. See Parisi and Luppi (2015) for a survey.

${ }^{2}$ For instance, Robson and Skaperdas (2008) introduce bias, argumentation costs and stake differences in a problem in which property rights are ambiguously defined. Bernardo et al. (2000) study several types of legal presumptions (e.g., pro-defendant or pro-plaintiff bias), and extend the analysis to include beliefs. De Mot (2013) analyses litigation expenditures under comparative and contributory negligence. Guerra et al. (2018) extend the "rent-seeking" success function to investigate the role of case merit relatively to the standard of proof. Parisi (2002) compares the adversarial with the inquisitorial procedure.

${ }^{3}$ Under the American system, each party bears their own legal costs, while under the English system, the losing party at trial pays the fees of the winning party. See Braeutigam et al. (1984), Katz (1987) and Plott (1987) for early game theory approaches to fee shifting systems, while Katz and Sanchirico (2011) survey the fee shifting literature.

${ }^{4}$ This limitation is robust for all argumentation technologies used in the litigation literature and for their extensions (Baik, 1994; Bernardo et al., 2000; Hirshleifer and Osborne, 2001; Kobayashi and Lott, 1996). For instance, Luppi and Parisi (2012) and Carbonara et al. (2015) deal with this limitation by considering that the winner's costs are only partially reimbursed. In their context, such an assumption is not unfounded and avoids considering of the most extreme version of the English fee shifting system.

${ }^{5}$ For example, under the English system with the traditional CSF (see Expression (2) below) and constant returns to scale, both litigants equilibrium efforts converge to $\infty$,
} 
issue gains even more relevance because the English system is the most common fee-shifting system, and in reality we observe that disputes do reach trial.

These observations call for an alternative contest success function, which should be flexible enough to study the English system and other cases in a systematic and meaningful way.

In the present paper, we propose a new and alternative Litigation Success Function (LSF) that resolves the limitations of the commonly employed CSF in dealing with the English fee shifting system in an analytically tractable model. This is the main contribution of the present paper. Individuals with strong arguments proceed to litigation regardless of the possibility that they might end up paying all the litigation costs. The decision to file a lawsuit and defend it depends on the individual arguments and not on the argumentation technology.

The present paper introduces a qualitative dimension into the argumentation effort of the plaintiff and the defendant. In this context, arguments are statements, which may include witnesses and actual testimonies (among other aspects), used to persuade someone or in support of a claim. However, they are not perfect, and part of these arguments can be exploited by the opponent to construct their own arguments. In other words, persuasion builds on the intrinsic and immutable strength of the individual's own arguments and on the weaknesses (or lack of strength) of the opponent's arguments. ${ }^{6}$

Qualitative considerations in the litigation process, such as the ones in the present paper, are new to the literature. The usual approach assumes that individuals have different merits or degrees of fault. This interpretation

which implies that the expected payoffs converge to $-\infty$, and no case reaches trial under the English system (Note: the equilibrium is obtained asymptotically for $\alpha \uparrow 1$ and holds true for any parameterization). In other words, the plaintiff is better off providing no argumentation effort and obtaining a null payoff. On the other hand, with the LSF proposed in this paper (see Expression (1) below) and constant returns to scale both litigants equilibrium efforts and expected payoffs equal $v / 4>0$, and we have active litigation in equilibrium (this equilibrium is obtained for $m=0, a=b=2 / 3$ and $v_{x}=v_{y}=v$ ). In other words, the dispute reaches trial.

${ }^{6} \mathrm{~A}$ branch of the literature employs Bayesian models to capture the persuasion process, see Daughety and Reinganum (1999) for a discussion in the context of economics and law, and Skaperdas and Vaidya (2012) for an approach with roots in the "rent-seeking" literature. 
is intuitively connected to the idea of argumentation quality. However, in technical terms both approaches are different because argumentation imperfections can be exploited by the opponent, which creates further strategic considerations.

In terms of the results obtained, we found that the fee-shifting system has a clear effect on the efforts and decision to file and contest lawsuits. The English system discourages nuisance suits by the party with lower chances of winning, which is often the party with the weaker arguments. We also found that competitive suits in which both parties hold strong arguments are unlikely to be contested because the defendant anticipates high argumentation intensity, and consequently a strong likelihood of losing and ending up paying all the litigation costs. These results are in line with the existing literature but introduce a qualitative dimension (Katz and Sanchirico, 2011; Rosenberg and Shavell, 1985; Shavell, 1982).

For the cases that reach trial, argumentation efforts are always higher under the English system than under the American system (Braetigam et al., 1984; Farmer and Pecorino, 1999; Katz and Sanchirico, 2011). We also found that the party with better arguments spends more effort than the opponent under the English system, and enjoys a higher probability of winning at trial.

Under both systems, for cases that reach trial, improvements in the strength of arguments lead to an intensification of the argumentation efforts. However, the expected payoff increases with the strength of the individual's own arguments only if these arguments are strong enough and the value under dispute sufficiently important. Otherwise, under the English system, the increased argumentation reduces the expected payoff because the total effort (the sum of both individuals' efforts) increases relatively faster than the individual's prospects of winning. The consideration of these effects is new to the literature.

The proposed LSF is also flexible enough to accommodate litigation specific aspects, such as, for example, bias and other merits, the possibility of settlement, cost and stake differences, among others. In this context, we also show how to introduce the worldwide-accepted presumption of innocence in favor of the defendant without affecting the analytical tractability of the problem. In addition, we found that settlement reduces the number of cases that reach trial but does not affect the intensity of litigation for those cases that do reach trial. Our results support the idea that the English system provides stronger settlement incentives than the American system (Coursey 
and Stanley, 1988; Katz and Sanchirico, 2011; Shavell, 1982; Snyder and Hughes, 1990).

Lastly, we note that the proposed LSF is new to the "rent-seeking" literature and is not limited to the study of litigation problems. It can be applied to general problems, in particularly to situations in which part of the individuals' efforts spillover to the opponent as, for example, in R\&D races, among other situations.

The paper is organized as follows. Section 2 presents the litigation success function. Sections 3 and 4 analyze the American and the English system, respectively. Section 5 discusses extensions. Section 6 compares both feeshifting systems. Section 7 concludes. The proofs of the main results are in Appendix.

\section{The litigation success function}

The litigation process is not indifferent to the identity of the individuals. The plaintiff is somebody not satisfied with the current status quo outcome. Consequently, he/she may file a claim in a court of law in an attempt to change the current status quo to a better outcome. In other words, he/she claim for a loss/compensation of value $v_{x}>0$ (the subscript $x$ denotes the plaintiff). In contrast, the defendant is somebody satisfied with the current status quo outcome. Nonetheless, he/she may has to spend costly effort in order to preserve it. The value of the dispute for the defendant is $v_{y}>0$ (the subscript $y$ denotes the defendant). ${ }^{7}$

The litigation success function (LSF) - The justice system is not perfect because, in most cases, absolute proof is impossible. A "not guilty" verdict means that the standard for rejecting innocence has not been met. ${ }^{8}$ In this

\footnotetext{
${ }^{7}$ We assume asymmetric stakes, but symmetric argumentation costs. There is some equivalence between these two. For instance, an increase in the costs is qualitatively equivalent to a decrease in the stakes. Dari-Mattiacci et al. (2015) study asymmetries in rent-seeking. Symmetry simplifies the analysis.

${ }^{8}$ Guerra et al. (2018) analyze the interrelation between different standards of proof, effort effectiveness and merits on the parties' litigation expenditures, cases brought to the courts, pretrial negotiations and preemptive strategies.
} 
complex process, the more resources an individual devotes to producing arguments, the more likely he or she is to influence the court's decision in their favor, with expenditures being converted into legal arguments by means of some argumentation technology.

In this context, the "rent-seeking" CSF is frequently used to aggregate these aspects and capture the complexity of the litigation process. However, in litigation, an infinite amount of argumentation effort may not be enough to guarantee a sure win. The quality of the individual's and the opponent's arguments are crucial to the final outcome. Consequently, contrary to what is implicit in the "rent-seeking" CSF, both parties' chances of winning may be bounded by the strength of their arguments.

In what follows, we present a new and alternative contest success function, which we call litigation success function. This LSF complements some limitations of the "rent-seeking" CSF (see the discussion below and in the Introduction). Let $x$ and $y$ denote the legal expenditures spend by the plaintiff and defendant, respectively. The probability that the plaintiff prevails at trial is given by:

$$
p(x, y)=\frac{a x^{\alpha_{x}}+(1-b) y^{\alpha_{y}}}{m+x^{\alpha_{x}}+y^{\alpha_{y}}} .
$$

where the parameters $\alpha_{x}$ and $\alpha_{y}$ measure the relevance of the effort with respect to randomness in the final outcome or the returns to effort (see e.g., Dari-Mattiacci and Parisi, 2014). For instance, $\alpha_{x}>\alpha_{y}$ means that the plaintiff has access to a better argumentation technology (e.g., a more skilled lawyer or law firm) than the defendant. In order to keep the model tractable, we assume constant returns to scale in the production of legal arguments, i.e., $\alpha_{x}=\alpha_{y}=1$.

The parameter $m \in \mathbb{R}$ can be used to introduce bias in favor of one of the litigants. For instance, any choice of $m>0$ introduces a bias in favor of the defendant (e.g., the presumption of innocence which is common to many legal proceedings - the burden of proof lies with the accuser), ${ }^{9}$ while $m<0$ introduces a bias in favor of the plaintiff. In order to simplify the

\footnotetext{
${ }^{9}$ In Section 5, we consider an alternative way to introduce the presumption of innocence in favor of the defendant. Note also that the introduction of a constant in the denominator of the LSF can also be associated with the possibility of "draw" (Blavatskyy, 2010; Dasgupta and Nti, 1998; Amegashie, 2006).
} 
equilibrium expressions, in what follows, we assume that $m=0$. This is the most natural approach to model general disputes or civil proceedings (e.g. divorce or breach of contract), in which there is no presumption of innocence.

Argumentation strength - The main aspect that distinguishes our approach from the litigation literature that employs the "rent-seeking" CSF are the parameters $a, b \in(1 / 2,1]$, which represent the intrinsic and immutable strength of the plaintiff and defendant's arguments, respectively. ${ }^{10}$ These parameters introduce a qualitative dimension into the argumentation of the plaintiff and defendant, respectively.

Argumentation strength is motivated by the fact that arguments are not perfect and part of them can be exploited by the opponent to build their own arguments. In other words, argumentation is a persuasion process that builds on the strength of the individual's arguments and on the weaknesses of the opponent's arguments. The parameters $a$ and $b$ capture this interactive process; they represent the intrinsic and immutable fraction of the plaintiff's and defendant's argumentation, respectively, that is solid, well-founded and persuasive. The remaining proportion of the plaintiff's and defendant's arguments, i.e., $1-a$ and $1-b$, respectively, is not solid, well-founded and persuasive, and can be exploited by their opponents. ${ }^{11}$

For instance, a high value of $a$ means that the plaintiff has strong arguments in support of a favorable outcome. However, this is not enough. In addition, the plaintiff must provide costly effort in support of its arguments (i.e., $x$ ) and must also take into consideration the strength of the defendant's arguments (i.e., $b$ ).

In this context, from the total argumentation effort produced by the plaintiff and the defendant, i.e., $x$ and $y$, respectively, the actual persuasion is given by $a x+(1-b) y$ and $(1-a) x+b y$, respectively, which are the nu-

\footnotetext{
${ }^{10}$ Note that the original Tullock's (1980) "rent-seeking" CSF is a particular case of (1) obtained by letting $a=b=1$ and $m=0$.

${ }^{11}$ In our context, $a$ and $b$ are common knowledge to both litigants. This assumption is not restrictive. Alternatively, we could have considered some uncertainty about the exact values of the parameters $a$ and $b$. Such approach would require to replace $a$ and $b$ by their expected values and the introduction of beliefs. Similarly, $a$ and $b$ are constants. However, we could have considered that they improve with the argumentation efforts. In this case, the values of $a$ and $b$ would be increasing functions of the litigants effort $x$ and $y$, respectively, i.e., $a(x)$ and $b(y)$. Other variations of the baseline model are also possible, see Section 5.
} 
merators of $p(x, y)$ and $1-p(x, y)$, respectively. Consequently, since part of the argumentation may spillover to the opponent, weak arguments affect crucially the chances of winning, which makes the decision to file a lawsuit and the argumentation process more selective and strategic. In this context, before entering into a dispute, individuals must consider not only the intrinsic and immutable characteristics of their own argument, but also of their opponents. $^{12}$

Some properties - In addition to introducing argumentation strength into the litigation process, which is an important qualitative aspect, the LSF (1) is practical and the addictive specification is interesting because of its mathematical simplicity and flexibility, a factor which is crucial for applied work.

The LSF (1) also satisfies a set of desirable properties that have been considered as standard requirements in the literature (Clark and Riis, 1998; Skaperdas, 1996). For instance, it satisfies monotonicity, i.e., it is increasing in the individual's effort and decreasing in the opponent's effort for $a, b \in(1 / 2,1]$ (i.e., $\partial p(x, y) / \partial x>0$ and $\partial p(x, y) / \partial y<0$, respectively). ${ }^{13}$ The LSF is also monotonically increasing in the strength of the individual's own arguments, and monotonically decreasing in the strength of the opponent arguments (i.e., $\partial p(x, y) / \partial a>0$ and $\partial p(x, y) / \partial b<0$, respectively). In addition, it also satisfies imperfect discrimination (i.e., positive effort implies a positive probability of winning) and independence of the irrelevant alternatives (i.e., only the efforts of the parties involved matter).

Another property of the proposed LSF is that the individuals' winning probabilities are bounded from above and below. In order to see this, simply note that for any $x \geqslant 0$ and $y \geqslant 0$ we have $p(x, y) \in[1-b, a]$ and $1-p(x, y) \in$ $[1-a, b]$. In other words, the individual's chances of winning are bounded

\footnotetext{
${ }^{12}$ We note that the proposed LSF (1) can be applied to problems other than litigation, and in areas of study outside of law and economics. For instance, general situations in which part of the individuals' efforts spillover to the opponents can also be studied with the LSF (1) (e.g., technological spillovers in R\&D races). The LSF in this paper is new to the "rent-seeking" literature.

${ }^{13}$ The parameters $a$ and $b$ should be larger than $1 / 2$. Otherwise, an individual argumentation effort would favor the opponent more than the individual his or herself. We can allow for such a possibility, however, in those cases we would have negative argumentation efforts in equilibrium (see Sections 3 and 2 below).
} 
from above by the strength of their own arguments and from below by the strength of the opponent's arguments. ${ }^{14}$

This property of the LSF (1) is motivated by the fact that the justice system is not perfect and because, in most cases, absolute proof is impossible. The "not guilty" verdict simply means that the standard for rejecting innocence was not met. Clearly, the greater the argumentation efforts, the greater the likelihood of the individual influencing the court's decision in their favor. However, there are limits on the capacity to influence the court's decision. The reason is that in litigation, even an infinite amount of argumentation efforts may not be enough to guarantee a sure win or to reveal the truth. The strength of the individual's and opponent's arguments are determinant for the final outcome. This is the crucial aspect that the LSF in this paper introduces into the litigation literature. Consequently, in our context, contrary to the "rent-seeking" CSF, both parties' chances of winning are bounded from above and below.

The contest success function (CSF) - In order to situate the reader in context, we conclude this section by commenting on the "rent-seeking" CSF and its application to litigation problems.

In its most general form, the "rent-seeking" CSF is given by:

$$
p(x, y)=\frac{\sigma F h(x)}{\sigma F h(x)+(1-F) h(y)}
$$

where $h(x)$ is some increasing function on the individual's effort $x$, which is frequently assumed as $h(x)=x^{\alpha} \cdot{ }^{15}$ The parameter $F \in(0,1)$ is interpreted as the plaintiff merit or the defendant degree of fault, while $\sigma>0$ is interpreted as a bias in favor/against the defendant. For instance, we might have $F \in$ $(0,1), \sigma=1$ and $h(x)=x^{\alpha}$, as in Hirshleifer and Osborne (2001), or $F=1 / 2$, $\sigma>0$ and $h(x)=x^{\alpha}$, as in Farmer and Pecorino (1999), among others.

However, none of these formulations can address the English fee-shifting system meaningfully and in a tractable model. The CSF (2) delivers active

\footnotetext{
${ }^{14}$ Bounds in the plaintiff's and the defendant's probabilities of winning also appear in Plott (1987). He assumes that part of the legal system cannot be influenced by the lawyers' efforts.

${ }^{15}$ One exception is $h(x)=e^{k x}$, where $k>0$ is some constant (Hirshleifer, 1989). However, the "logistic" specification is eminently numerical and for that reason has not been applied to study litigation problems.
} 
litigation in the trial stage under the English system only if $\alpha<1 / 2$ (Farmer and Pecorino, 1999), but for any $\alpha \neq 1$ the model is only tractable in the most symmetric case (i.e., symmetric valuations, argumentation costs and outside options). The introduction of more realistic assumptions is difficult without recourse to numerical methods. The choice $\alpha=1$ makes the model tractable but inadequate for addressing the English system because it delivers no litigation in equilibrium. However, in reality we do observe active litigation under the English fee-shifting system. This is where it lies the problem of using the CSF (2) in litigation.

The LSF (1) proposed in this paper solves these limitations. Under the English system the model delivers active litigation for $\alpha=1$ (the most common case in applied work). Consequently, we can introduce asymmetries and other realistic assumptions (e.g., pro-defendant or pro-plaintiff bias, settlement, different [sunk] fixed costs of bringing the suit, and other aspects that are common in legal disputes) without affecting the analytical characteristics of the model. Consequently, the LSF in this paper expands the spectrum of theoretical problems that can be analyzed in a tractable manner.

Lastly, the LSF (1) and the CSF (2) are similar in terms of results and intuition, because of possible links between argumentation strength ( $a$ and $b$ ) and merits $(F)$ or bias $(\sigma)$. This is a desired property because most of the existing results are robust and match the observed reality (Katz and Sanchirico, 2011; Parisi and Luppi, 2015). However, in technical terms both approaches are different. Under the LSF (1) the decisions to file and defend a lawsuit become more dependent on aspects related to the argumentation quality, and less dependent on the argumentation technology. The dependence of the CSF on these aspects is pointed out by Plott (1987), among other authors.

\section{The American system: baseline model}

A crucial aspect in litigation is how fees are allocated among the parties involved. The literature considers two extreme systems with some intermediate cases also being possible. Under the American system, each litigant bears his/her own legal costs, while under the English system the losing party pays the legal costs of the winning party. In this section, we focus on the American system. 
The Problem - Under the American system, the plaintiff chooses $x^{a m}$ to maximize the expected trial payoff net of argumentation costs (the superscript "am" denotes the American system):

$$
\pi_{x}^{a m}=p^{a m} v_{x}-x^{a m}
$$

subject to the participation constraint: $\pi_{x}^{a m}>0$. We assume that the argumentation expenditures unit cost is linear and equal to one. Similarly, the defendant chooses $y^{a m}$ to maximize the expected trial payoff net of argumentation costs:

$$
\pi_{y}^{a m}=\left(1-p^{a m}\right) v_{y}-y^{a m}
$$

subject to the participation constraint: $\pi_{y}^{a m}>0 .{ }^{16}$ Therefore, the plaintiff's decision to bring the suit and the defendant's decision to defend it depend on the trade-off between the expected gains from litigation and the zero (normalized) payoff from producing no argumentation efforts.

Note that the participation constraints are obtained assuming that if the plaintiff decides not to provide argumentation efforts, which is equivalent to not bringing the case to court, the defendant obtains the full payoff. Similarly, if the plaintiff decides to bring the case to court, but the defendant provides no argumentation efforts to defend the case, the plaintiff obtains the full payoff. These assumptions imply that both individuals' outside options are null, i.e., $\pi_{x}^{a m}>0$ and $\pi_{y}^{a m}>0$. This case corresponds to the baseline model. In Section 5.1, we extend this baseline model by introducing bias in favor of the defendant into the outside option. ${ }^{17}$

Argumentation Efforts and Payoffs - The associated system of first order conditions implies the following unique solution:

$$
x^{a m}=\frac{r(a+b-1)}{(1+r)^{2}} v_{x},
$$

\footnotetext{
${ }^{16}$ The specification of the defendant problem follows Corchón (2007), Hirshleifer and Osborne (2001), Konrad (2009), among others. Other authors consider an alternative, but equivalent, specification of the defendant problem, i.e., $\max _{y^{a m}}-p^{a m} v_{y}-y^{a m}$ subject to $-p^{a m} v_{y}-y^{a m}>-v_{y}$.

${ }^{17}$ In mathematical terms, these assumptions are equivalent to the statements. If $x=0$ and $y>0$, then $p(0, y) \equiv 0$, and $1-p(0, y) \equiv 1$. Likewise, if $x>0$ and $y=0$, then $p(x, 0) \equiv 1$, and $1-p(x, 0) \equiv 0$. Otherwise, if $x>0$ and $y>0$, then $p(x, y)$ follows the LSF (1).
} 
and,

$$
y^{a m}=\frac{r(a+b-1)}{(1+r)^{2}} v_{y},
$$

where $r \equiv v_{y} / v_{x} \in(0, \infty)$ measures the defendant/plaintiff valuation ratio. The values $x^{a m}$ and $y^{a m}$ are strictly positive for $a, b \in(1 / 2,1]$.

In terms of comparative statics, the individual argumentation effort increases with the individuals argumentation strength (as well as with their own valuation for the dispute). This is due to the non-cooperative nature of the litigation problem that induces an escalation in the intensity of mutual argumentation efforts when the strength of either party's arguments improves.

Moreover, if the defendant valuation $v_{y}$ (respectively, the plaintiff valuation $v_{x}$ ) increases, the plaintiff's argumentation effort $x^{a m}$ (respectively, the defendant's $y^{a m}$ ) increases if $r<1$ (respectively, $r>1$ ). In other words, the individual's valuation for the dispute must be sufficiently high in order to increase the argumentation effort after the increase in the opponent's valuation.

The highest level of mutual effort occurs when valuations are similar, i.e., $r \approx 1$, and the strength of arguments is high.

The expected payoffs for the plaintiff and defendant are obtained by plugging (5) and (6) into (3) and (4), respectively, in order to obtain:

$$
\pi_{x}^{a m}=\frac{a+2(1-b) r+(1-b) r^{2}}{(1+r)^{2}} v_{x}
$$

and,

$$
\pi_{y}^{a m}=\frac{1-a+2(1-a) r+b r^{2}}{(1+r)^{2}} v_{y}
$$

respectively.

In terms of comparative statics, payoffs increase with the strength of the individual's own arguments and valuation, but decrease with the strength of the opponent arguments and valuation.

Participation - Under the American system, the plaintiff and the defendant participation constraints are always satisfied. In other words, the plaintiff always files a claim and both parties incur in costly argumentation. 
Proposition 1. Under the American system in equilibrium there is always active litigation.

Full participation is also obtained under the commonly used "rent-seeking" CSF (2). Consequently, Proposition 1 confirms the robustness of this result. Intuitively, the reason is that under the American system, both parties have full control over their argumentation costs. For instance, if the dispute is not very relevant for the individual, the individual can always choose a lower level of argumentation effort, and vice versa, therefore, incurring costs that are proportional to the value of the dispute. Consequently, the intensity of argumentation is never high enough to affect participation.

We will see that under the English system this is no longer true, because in addition to the individual's own argumentation costs, individuals may end up paying the opponent's argumentation costs as well.

Lastly, the result that all cases proceed to litigation under the American system is counterfactual. In reality, many cases are not disputed or even settled. However, this problem is easy to solve - the realistic assumption that disputes involve fixed costs, in addition to the usual argumentation costs, is enough to guarantee that some cases do not proceed to trial. Another possibility is to allow explicitly for settlement of litigation (see Section 5).

\section{The English system: baseline model}

The English system is meant to force the involved parties to internalize some of the costs associated with the decision to bring suit (e.g., taxpayers and legal system costs, among other costs). Under this system, the losing party at trial pays the fees of the winning party. Consequently, individuals do not have full control over the argumentation costs. This uncertainty has implications for the individuals' incentives to file and contest lawsuits.

The Problem - Under the English system, the plaintiff chooses $x^{e n}$ to maximize the expected trial payoff net from their own and their opponent's expected argumentation costs (the superscript "en" denotes the English system):

$$
\pi_{x}^{e n}=p^{e n} v_{x}-\left(1-p^{e n}\right)\left(x^{e n}+y^{e n}\right),
$$


subject to the participation constraint: $\pi_{x}^{e n}>0$. Similarly, the defendant chooses $y^{e n}$ to maximize the expected trial payoff net from the own and the opponent's argumentation expected costs:

$$
\pi_{y}^{e n}=\left(1-p^{e n}\right) v_{y}-p^{e n}\left(x^{e n}+y^{e n}\right),
$$

subject to the participation constraint: $\pi_{y}^{e n}>0 .{ }^{18}$

The participation constraints are obtained as in Section 3 by assuming no bias or presumption of innocence. If a litigant decides not to produce arguments, he or she obtains the zero (normalized) payoff.

Argumentation Efforts and Payoffs - The associated system of first order conditions imply the following unique solution:

$$
x^{e n}=\frac{(1-b)(a+b-1) r}{(1-b+(1-a) r)^{2}} v_{x},
$$

and,

$$
y^{e n}=\frac{(1-a)(a+b-1) r}{(1-b+(1-a) r)^{2}} v_{y},
$$

where, $x^{e n}$ and $y^{e n}$ are strictly positive for $a, b \in(1 / 2,1]$.

Under the English system, the obtained equilibrium is not symmetric. The party with better arguments produces more argumentation, and enjoys a higher probability of success at trial under the English system than under the American system (see Section 6).

In terms of comparative statics, the argumentation efforts increase with the individual's own argumentation strength and that of their opponent (as well as with their own valuation for the dispute). ${ }^{19}$ Moreover, an increase in the defendant (respectively, plaintiff) valuation, increases the plaintiff (respectively, defendant) argumentation effort if $r<(1-b) /(1-a)$ (respectively, $r>(1-b) /(1-a))$. In other words, the opponent's valuation for the dispute

\footnotetext{
${ }^{18}$ As mentioned above, the specification of the defendant's problem is in line with Corchón (2007), Hirshleifer and Osborne (2001), Konrad (2009), among others. Other authors consider an alternative but equivalent specification of the defendant problem, i.e., $\max _{y^{e n}}-p^{e n} v_{y}-p^{e n}\left(x^{e n}+y^{e n}\right)$ subject to $-p^{e n} v_{y}-p^{e n}\left(x^{e n}+y^{e n}\right)>-v_{y}$.

${ }^{19} \mathrm{We}$ can show that if $\partial x^{e n} / \partial b<0$ (respectively, $\partial y^{e n} / \partial a<0$ ), then the constraint (15) (respectively, constraint (16)) fails. Therefore, we always have $\partial x^{e n} / \partial b>0$ and $\partial y^{e n} / \partial a>0$ if there is active litigation.
} 
increases their argumentation effort if the value of the dispute is sufficiently important for them.

These results are similar to the ones obtained under the American system. However, the argumentation intensity has implications in the participation decision. Since individuals have no control over the opponent's production of arguments, an individual with weak arguments is less likely to participate in an "English system type dispute" because they may end up paying the opponent's litigation costs. This issue is analyzed in more detail below.

The plaintiff and defendant equilibrium expected profits are obtained by replacing (11) and (12) into (9) and (10), to obtain:

$$
\pi_{x}^{e n}=\frac{a(1-b)^{2}+2(1-a)(1-b)^{2} r-(1-a)\left(a+b^{2}-1\right) r^{2}}{(1-b+(1-a) r)^{2}} v_{x},
$$

and,

$$
\pi_{y}^{e n}=\frac{(1-a)^{2} b r^{2}+2(1-a)^{2}(1-b) r-(1-b)\left(a^{2}+b-1\right)}{(1-b+(1-a) r)^{2}} v_{y}
$$

respectively.

The plaintiff (respectively, defendant) expected payoff increases with the strength of their own arguments if $r<(1-b) /(1-a)$ (respectively, $r>$ $(1-b) /(1-a))$, i.e., when the strength of their own arguments is relatively strong and the value under dispute sufficiently important. ${ }^{20}$ Otherwise, the argumentation escalation effect reduces the individual payoff even after an improvement in the strength of their own arguments. In other words, the total effort (the sum of both efforts) increases relatively more than the wining prospects, and consequently the expected cost increases reducing the expected payoff. These effects do not exist under the American system (Section 3), in which an improvement in the strength of the individual's own arguments always increases the expected payoff. The consideration of these effects explains why participation is less likely under the English than under the American system.

Simultaneously, the expected payoff decreases with the opponent's argumentation strength and valuation for the dispute, but increases with their own valuation.

\footnotetext{
${ }^{20}$ This issue is easier to see in the case of symmetric valuations, i.e., $r=1$. In this case the inequality reduces to $a>b$ (respectively, $a<b$ ).
} 
Participation - An interior solution with active litigation requires that both participation constraints be simultaneously satisfied. In contrast to the American system, in the English system participation is not always guaranteed. For instance, if the plaintiff expects a negative profit from litigation, he/she will not file a claim because the zero outside option is better. The same happens with the defendant.

In technical terms, the plaintiff's participation constraint, $\pi_{x}^{e n}>0$, is satisfied if:

$$
0<r<r_{x} \equiv \frac{a(1-b)}{(a+b-1)(1-a)^{1 / 2}-(1-b)(1-a)},
$$

while the defendant's participation constraint, $\pi_{y}^{e n}>0$, is satisfied if:

$$
r_{y} \equiv \frac{(a+b-1)(1-b)^{1 / 2}-(1-b)(1-a)}{b(1-a)}<r<\infty .
$$

These constraints depend on the relative difference between $a$ and $b$ in a non-linear way. However, since expected payoffs are closely related with the participation incentives, the factors that affect payoffs, also affect participation in the same direction. The strength of the individual's own arguments increases the individual's participation, while the strength of the opponent's arguments decreases the individual's participation.

Similarly, each constraint is more likely to be satisfied when the relative value of the dispute is sufficiently important for the individual, i.e., low $r$ for the plaintiff and high $r$ for the defendant.

Equilibrium Existence and Sequential Structure - In technical terms, under the English system, when one (or both) of the participation constraints (15) and (16) is not satisfied, the equilibrium fails to exist. In this context, we must distinguish between the cases in which the plaintiff proceeds or not with the claim via the legal system and the cases in which the defendant prepares or not a costly defense. This issue was not a problem under the American system because mutual participation was always guaranteed.

In order to deal with the possibility of equilibrium inexistence, Farmer and Pecorino (1999) suggest passing from a simultaneous to a sequential structure, in which the party with a satisfied participation constraint moves first. We consider a similar approach, but in which the plaintiff is always the first mover. This is the most natural approach in litigation because the 


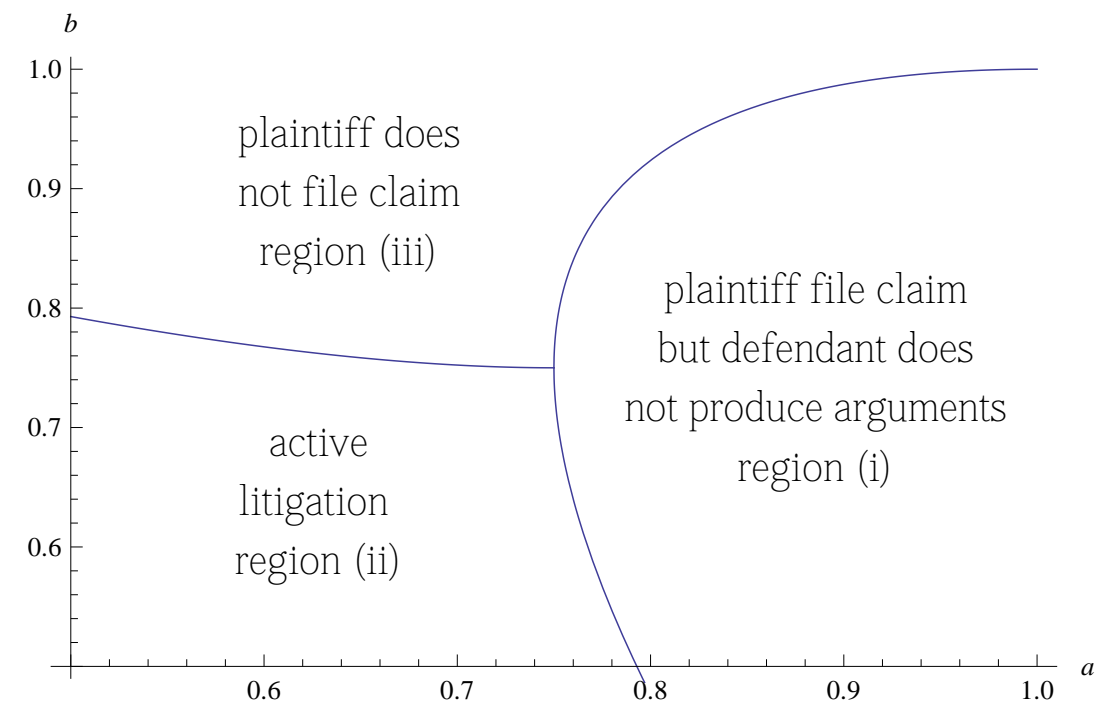

Figure 1: The English system equilibria configurations for $r=1$ (the horizontal and vertical axes measure the quality of the arguments of the defendant and plaintiff, $a$ and $b$, respectively).

plaintiff is the one that ultimately decides whether or not to file a lawsuit (Carbonara et al., 2015; Hirshleifer and Osborne, 2001). Therefore, in order to guarantee equilibrium existence, we consider the following sequential structure:

Stage 1 (lawsuit): The plaintiff decides whether or not to file the lawsuit, i.e., $x^{e n}>0$ or $x^{e n}=0$, respectively. In the latter case the game ends with the payoffs $\pi_{x}^{e n}=0$ and $\pi_{y}^{e n}=v_{y}$ for the plaintiff and the defendant, respectively. Otherwise, the case proceeds to the defense stage 2 .

Stage 2 (defense): The defendant decides whether or not to prepare a costly defense in response to the plaintiff's allegations, i.e., $y^{e n}>0$ or $y^{e n}=0$, respectively. In the latter case there is no active argumentation and the game ends with expected payoffs $\pi_{x}^{e n}=v_{x}$ and $\pi_{y}^{e n}=0$ for the plaintiff and the defendant, respectively. Otherwise, the case proceeds to the litigation stage 3.

Stage 3 (trial): In case of active litigation, both the plaintiff and defendant simultaneously spend costly efforts to produce arguments, i.e., $x^{e n}>0$ 
and $y^{e n}>0$, respectively. The game ends with expected payoffs $\pi_{x}^{e n} \in\left(0, v_{x}\right)$ and $\pi_{y}^{e n} \in\left(0, v_{y}\right)$, given by expressions (13) and (14), respectively, for the plaintiff and the defendant, respectively.

The sequential problem is solved by backwards induction. The following result resumes our findings. The proof follows from the discussion.

Proposition 2. Under the English system;

(i) For $0<r<r_{y}$, in equilibrium the plaintiff files the claim, but the defendant does not spend resources producing arguments.

(ii) For $r_{y}<r<r_{x}$, in equilibrium the plaintiff files the claim and the defendant spends resources producing arguments.

(iii) Otherwise, in equilibrium the plaintiff does not file the claim.

Part (ii) of Proposition 2 shows that with the LSF (1) some cases reach the trial stage under the English system - with both the plaintiff and the defendant actively spending efforts to produce arguments. The litigation process reaches Stage 3. This case corresponds to Region (ii) in Figure 1. Under the English system, this result is not possible if we consider the CSF (2).

In Part (iii) of Proposition 2 the plaintiff does not file a lawsuit because the expected payoff is negative. The litigation process is not initiated, it ends in Stage 1. This case corresponds to Region (iii) in Figure 1.

In Part (i) of Proposition 2 the defendant prefers not to spend costly effort because the expected payoff is negative. The litigation process finishes in Stage 2. This case corresponds to Region (i) in Figure 1.

Under the English system, the winning party pays no argumentation costs while the losing party pays all the argumentation costs. This issue has crucial implications for the decision to file and contest lawsuits. The results in Proposition 2 reflect these considerations. The intuition can be seen in Figure 1 -active litigation occurs when the strength of the arguments of both parties is not too high, Region (ii). Otherwise, if the defendant's arguments are relatively stronger than the plaintiff arguments, i.e., $b \gg a$, the plaintiff prefers not to file the lawsuit because the likelihood of ending up losing and paying all the argumentation costs is high (Region (iii) in Figure 1). On the other hand, if the plaintiff's arguments are sufficiently strong (not necessarily much stronger than the defendant's arguments), then the defendant may prefer not to spent resources producing costly arguments either because the 
likelihood of losing is high or because he/she anticipates an escalation in argumentation that may turn out to be too costly (Region (i) in Figure 1). Therefore, as pointed out by Rosenberg and Shavell (1985), and many other authors, the English system discourages nuisance suits that have little or no chance of being won. We also found that very competitive suits in which both parties hold strong arguments are unlikely to be contested because of argumentation escalation effects.

The strategic considerations that justify the existence of Regions (i) and (iii) are absent under the American system because each party has full control over their own argumentation costs. For that reason, under this system Regions (i) and (iii) in Figure 1 vanish.

Note also that Region (i) is larger than Region (iii) in Figure 1 because the plaintiff benefits from a first-mover advantage. ${ }^{21}$ Consequently, the plaintiff is able to file competitive lawsuits in which both parties hold strong arguments, which they would otherwise not file, because they anticipate that the defendant will not participate.

\section{Extensions to the baseline model}

The LSF (1) proposed in this paper is flexible enough to accommodate litigation specific aspects such as bias and other merits (e.g., pro-defendant or pro-plaintiff bias), ${ }^{22}$ settlement, fixed and variable costs, and stake differences, among others. These issues can be introduced without affecting the analytical tractability of the problem.

In this section, we will show how to introduce the presumption of innocence in favor of the defendant and the possibility of settlement without great mathematical complexity.

\footnotetext{
${ }^{21}$ Region (i) includes the case in which both participation constraints (15) and (16) fail, and also the case in which only the defendant's participation (16) fails.

${ }^{22}$ Several types of trial specific bias have been suggested in the literature: pro-plaintiff, pro-defendant, hindsight and selection bias, among others. Priest and Klein (1984) suggest the existence of a selection bias in the sample of cases that go to trial. These cases are the ones in which the plaintiff is optimistic about his or her prospects of winning, see also Hughes and Snyder (1995). Waldfogel (1995) shows a prevalence of pro-plaintiff bias in economic disputes such as contracts and property rights, but not in tort cases.
} 


\subsection{The presumption of innocence}

The presumption of innocence in favor of the defendant is introduced by means of a better outside option. ${ }^{23}$ Intuitively, the defendant has some chances of being declared innocent, even without incurring in costly argumentation because the plaintiff was not able to prove their claims beyond "reasonable doubt".

In order to see it, if the plaintiff files a claim, i.e., $x>0$, and the defendant does nothing to defend it, i.e., $y=0$, then the LSF (1) becomes $p(x, 0)=a$. In other words, the defendant has a positive probability of winning $1-p(x, 0)=$ $1-a \in[0,1 / 2)$, even without engaging in costly argumentation effort. ${ }^{24}$ This observation can be interpreted as if there is a presumption of innocence bias in favor of the defendant, which implies a better outside option $(1-a) v_{y}-a x^{e n}$ for the defendant.

Since the equilibrium efforts obtained in Sections 3 and 4 remain unchanged, the approach is equivalent to replacing the defendant's participation constraint $\pi_{y}^{e n}>0$ by the new participation constraint $\pi_{y}^{e n}>(1-a) v_{y}-a x^{e n}$, where $x^{e n}$ approaches zero in equilibrium. Consequently, the defendant participation condition (16) is replaced by the new participation condition:

$$
r_{y}^{i} \equiv a^{1 / 2}(1-b)^{1 / 2} /(1-a)<r<\infty .
$$

This constraint is more restrictive than (16) because the presumption of innocence reduces the defendant's incentives to engage in costly argumentation by raising the cutoff value $r_{y}^{i}$ above $r_{y} .{ }^{25}$ The active litigation interval in Part (ii) of Proposition 2 becomes smaller, but with different implications for the

\footnotetext{
${ }^{23}$ An alternative approach is to consider $m>0$ in the LSF (1). Such approach is probably the most correct because it has some asymptotic properties that makes it more suitable to model the presumption of innocence. However, under the English system (but not under the American system), the obtained expressions can be large, which may difficult the intuition and the analysis of the results. For that reason, in this section, we consider a simpler way of introducing the presumption of innocence that does not require new computations, but only a change in the participation constraints.

${ }^{24}$ In mathematical terms, these observations are equivalent to the statements. If $x=0$ and $y>0$, then $p(0, y) \equiv 0$, and $1-p(0, y) \equiv 1$. But, if $x>0$ and $y=0$, then $p(x, 0)=a$ and $1-p(x, 0)=1-a$. Otherwise, if $x>0$ and $y>0$, then $p(x, y)$ follows the LSF (1).

${ }^{25} \mathrm{~A}$ necessary and sufficient condition for the existence of an equilibrium with active argumentation is the non-emptiness of the interval $\left(r_{y}^{i}, r_{x}\right)$. Such is the case for $a<$ $4(1-b) /(2-b)^{2}$.
} 
parties involved: the plaintiff may not win even with an infinite amount of arguments and the defendant may win even without making any effort.

\subsection{The settlement of Litigation}

The large majority of civil cases are settled before trial because trial substantially raises the costs of litigation, in particular, under the English system. In this context, the model should reflect that the likelihood of settlement depends on the associated fee shifting system.

In order to verify this effect, we can introduce the possibility of settlement, by considering that before deciding whether to file the lawsuit, there is a costly settlement negotiation stage. In this stage, if both parties agree on a settlement, the plaintiff obtains the payoff $\pi_{x}^{s}=f(a, b) v_{x}-c_{x}$, while the defendant obtains the payoff $\pi_{y}^{s}=(1-f(a, b)) v_{y}-c_{y}$, where $f(a, b) \in[0,1]$ is the fraction of the value under dispute that the plaintiff obtains and $1-f(a, b)$ is the fraction of the value under dispute that the defendant obtains. These fractions may depend on the strength of each individual arguments because better arguments imply more bargaining power. The parameters $c_{x} \geqslant 0$ and $c_{y} \geqslant 0$ correspond to the plaintiff and the defendant settlement negotiation costs, respectively. Therefore, the negotiations fail if the plaintiff settlement payoff $\pi_{x}^{s}$ is lower than the litigation expected payoff $\pi_{x}^{e n}$, i.e.,

$$
f(a, b) v_{x}-c_{x}<p^{e n} v_{x}-\left(1-p^{e n}\right)\left(x^{e n}+y^{e n}\right),
$$

and the opposite otherwise. In case of failure in negotiations, the problem follows the three stages sequential structure and efforts found in Section 4.

In this context, we can consider two cases:

(1) The case in which $f(a, b)$ is exogenously given. In this case, if the value of $f(a, b)$ is too low, such that $\pi_{x}^{s}<\pi_{x}^{e n}$, then settlement may fail and the plaintiff proceeds to litigation. In this case, settlement may fail because for some exogenous reason $f(a, b)$ is fixed at some level that makes settlement impossible.

(2) The case in which $f(a, b)$ is endogenous determined in equilibrium. In this case, in the perfect information equilibrium the defendant must propose a value $f(a, b)$ that makes the plaintiff indifferent between the settlement and the lawsuit, i.e., $\pi_{x}^{s}=\pi_{x}^{e n}$. Simultaneously, such offer must be incentive compatible for the defendant, i.e., $\pi_{y}^{s} \geqslant \pi_{y}^{e n}$. In other words, the defendant must be at least weakly better with the settlement than with the lawsuit. 
Therefore, negotiations fail only if the negotiations costs $c_{x}$ and $c_{y}$ are such that there is no value $f(a, b) \in[0,1]$ that satisfies simultaneously $\pi_{x}^{s}=\pi_{x}^{e n}$ and $\pi_{y}^{s} \geqslant \pi_{y}^{e n}$. Such situation is only possible if $c_{x}+c_{y}>x^{e n}+y^{e n}$, which is not usual the case because it is normally assumed that litigation is more expensive than settlement.

In this context, the active litigation region of Part (ii) of Proposition 2 shrinks (Part (ii) of Proposition 2 becomes $r_{y}<r<r_{x}^{s}$ where $r_{x}^{s} \leqslant r_{x}$ where $r_{x}^{s}$ is the cutoff that makes inequality (18) hold with equality). The possibility of settlement reduces the likelihood of the plaintiff filling a lawsuit.

The same reasoning applies to the American system.

Since the litigation expected payoffs are higher under the American system than under the English system (because effort is lower under the American than under the English system, see Proposition 3 below), settlement is going to be more likely under the English system. This observation is in line with the intuition that the English system provides stronger incentives for settlement (see Katz and Sanchirico, 2011; Shavell, 1982).

In this context, the introduction of settlement decreases the likelihood of litigation, but leaves unchanged the intensity of litigation.

\subsection{Other extensions to the baseline model}

The baseline model presented in this paper is able to capture sufficiently high levels of generality and asymmetry among litigants. For instance, litigants with different argumentation strengths, i.e., $a \neq b \in(1 / 2,1]$, and for litigants with different valuations, i.e., $v_{x}, v_{y}>0$.

In order to keep the model and the analysis intuitive and tractable, we had to introduce some simplifications. For instance, in the LSF (1) we have considered constant returns to scale, i.e., $\alpha_{x}=\alpha_{y}=1$, and we have removed the addictive bias, i.e., we have set $m=0$. However, we can relax these assumptions and consider other extensions of the original model like for example, decreasing and increasing returns to scale, i.e., $\alpha_{x}=\alpha_{y} \neq 1$, addictive bias, i.e., $m \neq 0$, or multiplicative bias. Of course, the consideration of so many possibilities will not lead to a simple and tractable model, and in some cases we may run into equilibrium multiplicity and existence problems, which are very common in the "rent-seeking" literature and will also appear in our framework. In other cases, we can recover tractability by imposing symmetry in either $a=b$ or $v_{x}=v_{y}$. Nonetheless, these extensions 
can be introduced into the LSF (1). ${ }^{26}$

Similarly, asymmetric information or pre-trial negotiations can be incorporated along the same lines as it is done in the "rent-seeking" literature.

In this context, we stress that the litigation success function in this paper is particularly suitable to handle the limitations of the usually employed contest success function in dealing with the English system, without imposing restrictions and additional complexity into the study of the American system, which is the most common framework in the "rent-seeking" literature. However, the litigation success function in this paper does not solve all limitations of the "rent-seeking" literature.

Lastly, we note that the proposed LSF is new to the "rent-seeking" literature and its application is not limited to the study of litigation problems. It can be applied to general problems different from litigation. In particular, it can be applied to situations in which part of the individuals' efforts spillover to the opponent as, for example, in $R \& D$ races in which part of the $R \& D$ effort made by one firm can be exploited by its opponents. In this context, $1-a, 1-b \in[0,1 / 2)$ are the fraction of this $\mathrm{R} \& \mathrm{D}$ effort that is captured by the opponents.

\section{Comparison between the American and English systems}

In this section, we compare the American and English systems in terms of argumentation efforts and probabilities of winning.

${ }^{26}$ For instance, the following formulation of the LSF:

$$
p(x, y)=\rho \frac{a x+(1-b) y}{x+y}
$$

shows a simple and tractable way to introduce a multiplicative bias $\rho \in[0,1]$, which can be used to capture situations in which one of the litigants has an advantage over the other (in this case, the defendant). In this context, under the English system the equilibrium litigation efforts would become:

$$
x^{e n}=\frac{(1-b)(a+b-1) \rho^{2} r}{(1-\rho b+\rho(1-a) r)^{2}} v_{x}, \text { and, } y^{e n}=\frac{(1-a \rho)(a+b-1) \rho r}{(1-\rho b+\rho(1-a) r)^{2}} v_{y},
$$

which introduces some changes with respect to (11) and (12), respectively. In terms of comparative statics, the plaintiff argumentation incentives would be more negatively affected than the defendant incentives. 
Proposition 3. For $r_{y}<r<r_{x}$, in equilibrium $x^{e n}>x^{a m}$ and $y^{e n}>y^{a m}$. Otherwise, in equilibrium $x^{a m}>x^{e n}=0$ and $y^{a m}>y^{e n}=0$.

The result states that when there is active litigation under both systems, then under the English system both parties provide more effort than under the American system. This observation is in line with the empirical evidence and the existing theoretical results (Braeutigam et al., 1984; Katz, 1987; among others). ${ }^{27}$

However, under the English system many disputes do not reach trial, i.e., the ratio $r$ is outside the interval $\left(r_{y}, r_{x}\right)$, in which case there is no active trial litigation. Therefore, under the English rule disputes are less likely to end up in trial.

In a nutshell, the English system discourages nuisance suits and reduces the costs for the legal system, but increases the individuals spending in those cases that proceed to trial. These countervailing effects lead to ambiguous conclusions in terms of welfare because argumentation efforts do not create value per se and is difficult to quantify the social and private benefits of justice.

In terms of the plaintiff's probabilities of winning, we have the following result.

Proposition 4. For $r_{y}<r<r_{x}$, in equilibrium $p^{e n}>1 / 2$ and $p^{a m}>1 / 2$, for

$$
r<\frac{1-b}{1-a} \frac{2 a-1}{2 b-1} \quad \text { and } \quad r<\frac{2 a-1}{2 b-1},
$$

respectively, and the opposite otherwise. Furthermore, $p^{e n}>p^{a m}$ if $a>b$, and the opposite otherwise.

The result shows that the party with better arguments and higher valuation has a higher probability of winning under both systems. Moreover, this party also has a higher probability of winning under the English than under the American system. Differences in the strength of argumentation play a more prominent role under the English system than under the American system, which is not surprising since the English system involves strategic considerations that are outside the individuals' control.

\footnotetext{
${ }^{27}$ The discussion dates back to the 18th century; see Braeutigam et al. (1984) for an early economic perspective on these issues and Katz and Sanchirico (2011) for a survey.
} 
For instance, if $a=3 / 4$ and $b=2 / 3$, i.e., the plaintiff argumentation strength is higher than the defendant, then in the case that $r=1$, we have $p^{e n}=0.57$ and $p^{a m}=0.54$. Alternatively, we can think that the plaintiff winning probability is higher than the defendant winning probability under weaker conditions in the English system than in the American system, i.e., $r<2$ and $r<3 / 2$, respectively.

Note also that if there are no differences in terms of individuals' valuations, the argumentation efforts of the plaintiff and defendant are the same under the American system, but not under the English system. In the English system, the party with the better arguments provides more effort.

\section{Conclusion}

As pointed out by Hirshleifer and Osborne (2001) there is no perfect way to represent litigation; social interactions are far too complex to be captured in a single expression. Nonetheless, the proposed LSF (1) offers a more realistic alternative in this direction. In addition to introducing explicitly a qualitative, intrinsic and immutable dimension in the argumentation process, it is able to deal with the English fee shifting system in a tractable and meaningful manner. Individuals with strong arguments proceed to litigation regardless of the possibility of ending up paying all the litigation costs.

The results in the present paper are general, intuitive and in line with the empirical evidence (Katz and Sanchirico, 2011; Parisi and Luppi, 2015). We found that fee shifting has a clear effect in the argumentation effort and in the decision to file and contest lawsuits. The present paper also brings new insights into the literature. For instance, the LSF in the present paper is the first to consider asymmetric valuations. We have also shown how to introduce the worldwide-accepted presumption of innocence in favor of the defendant and the possibility of settlement. In addition, the LSF suggested in the present paper is able to accommodate a set of additional and realistic considerations common to litigation, such as, for example, individual merits, pro-defendant or pro-plaintiff bias, different argumentation technologies (better or worse lawyers), different [sunk] fixed costs of bringing a suit, and other aspects common to legal disputes. These can be incorporated into the analysis without greater computational complexity while simultaneously pre-

serving the analytical characteristics of the model. Our approach includes 
a qualitative dimension and reduces the emphasis given to argumentation quantity.

As an overall conclusion, the English system discourages low value suits and reduces the costs for the society. However, a reduction in the litigation incentives might not be good for the society as a whole. On the other hand, the litigation effort increases for those cases that proceed to trial, which is likely to lead judges to take decisions that are more accurate. However, argumentation effort does not create value per se. Therefore, it could be optimal from a social welfare perspective that parties would settle agreement and not proceed to trial, but again, that could affect the incentives to misbehave. The answer to these questions is not straightforward, because it is difficult to measure the private and social benefits that individuals and society derive from justice. Nonetheless, and in spite of the fact that the quantification of these effects is challenging and eminently open to subjectivity, these issues should be the object of further research.

We hope that the present paper can, by introducing a more tractable and realistic model of litigation, provide a theoretical basis for the study of these and other challenging questions, and to improve our understanding on what might be the optimal fee-shifting systems.

Acknowledgments: Support from the GRODE project 2017SGR770, Spanish Ministerio of Ciencia y Innovación project ECO2016-75410-P (AEI/FEDER, UE) and the Barcelona GSE is gratefully acknowledged. I would like to thank Luis Corchón, Sara Leo Jové, David Rahman, Ricardo Ribeiro, Juan Pablo Rincón-Zapatero and Burkhard Schipper, as well as several seminars and congresses participants for helpful comments and discussions. All remaining errors are mine.

\section{Appendix: Proofs of the Propositions}

Proof of Proposition 1. We want to show that under the American system the equilibrium payoffs are always strictly positive. The maximization

of the expected payoffs in expressions (3) and (4), with respect to $x^{a m}$ and $y^{a m}$, respectively, returns the system of first order conditions:

$$
-1+\frac{(a+b-1) v_{x} y^{a m}}{\left(x^{a m}+y^{a m}\right)^{2}}=0 \text { and }-1+\frac{(a+b-1) v_{y} x^{a m}}{\left(x^{a m}+y^{a m}\right)^{2}}=0 .
$$


The solution of this system is the unique equilibrium efforts given by expressions (5) and (6). The second order condition for a maximum is trivially satisfied. Subsequently, replace (5) and (6) into (3) and (4) to obtain the equilibrium payoffs in expressions (7) and (8), respectively. Since $a, b \in(1 / 2,1]$, $v_{x}, v_{y} \in(0, \infty)$ and $r \equiv v_{y} / v_{x} \in(0, \infty)$, these payoffs are strictly positive, implying that under the American system there is always active litigation in equilibrium.

Proof of Proposition 2. We want to show that under the English system, depending on the value of the parameters, we may have different patterns of litigation. The maximization of the expected payoffs in expressions (9) and (10), with respect to $x^{e n}$ and $y^{e n}$, respectively, returns the system of first order conditions:

$$
-1+a+\frac{(a+b-1) v_{x} y^{e n}}{\left(x^{e n}+y^{e n}\right)^{2}}=0 \text { and }-1+b+\frac{(a+b-1) v_{y} x^{e n}}{\left(x^{e n}+y^{e n}\right)^{2}}=0 .
$$

The solution of this system is the unique equilibrium efforts given by expressions (11) and (12). The second order condition for a maximum is trivially satisfied. Subsequently, replace (11) and (12) into (9) and (10) to obtain the equilibrium payoffs in expressions (13) and (14), respectively. Since $a, b \in(1 / 2,1], v_{x}, v_{y} \in(0, \infty)$ and $r \equiv v_{y} / v_{x} \in(0, \infty)$, these payoffs are not always positive. The plaintiff's payoff is positive if $\pi_{x}^{e n}>0$ (i.e., the participation constraint is satisfied), which occurs (after some algebra) for $r<r_{x}$, where $r_{x}$ is given in (15). Similarly, the defendant's payoff is positive if $\pi_{y}^{e n}>0$ (i.e., the participation constraint is satisfied), which occurs (after some algebra) for $r>r_{y}$, where $r_{y}$ is given in (16). Then, in line with the proposed equilibrium existence sequential structure we have that: (i) if $0<r<r_{y}$ the defendant has no participation incentives, (iii) if $r_{x}<r<\infty$ the plaintiff has no participation incentives, and (ii) if $r_{y}<r<r_{x}$ both litigants have participation incentives. Finally, a necessary and sufficient condition for the existence of the equilibria in (i), (iii) and (ii) is the nonemptiness of the intervals $0<r<r_{y}, r_{x}<r<\infty$ and $r_{y}<r<r_{x}$, respectively, which is the case for $a^{2}+b>1, a+b^{2}>1$, and

$$
a b>\left((a+b-1) /(1-b)^{1 / 2}-(1-a)\right) /\left((a+b-1) /(1-a)^{1 / 2}-(1-b)\right),
$$

respectively. Some extensions of the LSF (1) or variations of the baseline model can widen or shrink these intervals. 
Proof of Proposition 3. In order to show that effort is higher under the English system than under the American system for $r_{y}<r<r_{x}$, i.e., the case in which there is active litigation in both systems, it suffices to show that $x^{e n}>x^{a m}$ (i.e., expressions (11) versus (5)) and $y^{e n}>y^{a m}$ (i.e., expressions (12) versus (6)) are always true in the region of interest, i.e., for $r \in\left(r_{y}, r_{x}\right)$. This result is obtained numerically. On the other hand, if $r$ is outside the interval $\left(r_{y}, r_{x}\right)$, then under the English system, one of the litigants has no participation incentives and there is no litigation in equilibrium, i.e., $x^{e n}=0$ and $y^{e n}=0$. Therefore, outside the interval $\left(r_{y}, r_{x}\right)$, we trivially have $x^{a m}>$ $x^{e n}=0$ and $y^{a m}>y^{e n}=0$.

Proof of Proposition 4. We want to show under which conditions the plaintiff has a higher winning probability. After replacing expressions (11) and (12) into the LSF (1) and expressions (5) and (6) into the LSF (1), we obtain that the plaintiff's winning probabilities under the English and American systems are given by $p^{e n}=(1-b)(a+(1-a) r) /(1-b+(1-a) r)$ and $p^{a m}=(a+(1-b) r) /(1+r)$, respectively. Then, solve $p^{e n}>1 / 2$ and $p^{a m}>1 / 2$ for $r$ to obtain the desired inequalities. Finally, manipulate the inequality $p^{e n}>p^{a m}$ to obtain the condition $a>b$.

\section{References}

Amegashie, P. (2006). "A contest success function with a tractable noise parameter." Public Choice, 126, 135-144.

Angenendt, D., and Robledo, J. (2015). "The Role of Firm Size in Choice and Enforcement of Patent Protection." mimeo.

Baik, K. (1994). "Effort levels in contests with two asymmetric players." Southern Economic Journal, 61, 367-378.

Bernardo, A., Talley, E., Welch, I. (2000). "A theory of legal presumptions." Journal of Law Economics and Organization, 16, 1-49.

Blavatskyy, P. (2010). "Contest success function with the possibility of a draw: Axiomatization." Journal of Mathematical Economics, 46, 267-276.

Braeutigam, R., Owen, B. and Panzar, J. (1984). "An economic analysis of alternative feeshifting systems." Law and Contemporary Problems, 47, 173-185.

Carbonara, E., Parisi, F., and von Wangenheim, G. (2015). "Rent-seeking and litigation: The hidden virtues of limited fee shifting." Review of Law \& Economics, 11(2), 113-148. 
Clark, D. and Riis, C. (1998). "Contest Success Functions: an Extension." Economic Theory, 11, 201-204.

Corchón, L. (2007). "The theory of contests: A survey." Review of Economic Design, 11, 69-100.

Coursey, D. and Stanley, L. (1988). "Pretrial Bargaining Behavior within the Shadow of the Law: Theory and Experimental Evidence." International Review of Law and Economics, 8, 161-179.

Dari-Mattiacci, G., Langlais, E., Lovat, B. and Parisi, F. (2015). "Asymmetries in Rent-Seeking." In R. Congleton and A. Hillman (Eds.), A Companion to Rent Seeking: Theory and Practice. Chap. 5, 73-92.

Dari-Mattiacci, G. and Parisi, F. (2014). "Returns to effort in rent-seeking games." Public Choice, 159, 99-104.

Dasgupta, A. and Nti, K. (1998). "Designing an optimal contest." European Journal of Political Economy, 14, 587-603.

Daughety, A. and Reinganum, J. (1999). "Stampede to Judgment: Persuasive Influence and Herding Behavior by Courts." American Law and Economics Review, 1, 158-189.

De Mot, J. (2013). "Comparative versus contributory negligence: A comparison of the litigation expenditures." International Review of Law and Economics 33, 54-61.

Farmer, A. and Pecorino, P. (1999). "Legal expenditures as a rent-seeking game." Public Choice, 100, 271-288.

Guerra, A., Luppi, B. and Parisi, F. (2018). "Standards of Proof and Civil Litigation: A Game-Theoretic Analysis." The B.E. Journal of Theoretical Economics.

Hirshleifer, J. (1989). "Conflict and rent-seeking success functions: Ratio vs. difference models of relative success." Public Choice, 63, 101-112.

Hirshleifer, J. and Osborne, E. (2001). "Truth, effort and the legal battle." Public Choice, 108, 169-195.

Hughes, J. and Snyder, E. (1995). "Litigation and Settlement under the English and American Rules: Theory and Evidence." Journal of Law and Economics, 38, 225-250.

Katz, A. (1987). "Measuring the Demand for Litigation: Is the English Rule Really Cheaper?" Journal of Law, Economics, and Organization, 3, 143-176.

Katz, A. (1988). "Judicial decision making and litigation expenditure." International Review of Law and Economics, 8, 127-143. 
Katz, A. and Sanchirico, C. (2011). "Fee shifting in litigation: survey and assessment," in Chris W. Sanchirico (eds), Elgar Encyclopedia of Law and Economics, Volume X, Procedural Law and Economics, Edward Elgar, MA, USA.

Kobayashi, B. and Lott, J., Jr. (1996). "In defense of criminal defense expenditures and plea bargaining." International Review of Law and Economics, 16, 397-416.

Konrad, K. (2009). Strategy and Dynamics in Contests, New York: Oxford Univ. Press.

Luce, R. (1959). Individual choice behavior. New York: Wiley.

Luppi, B. and Parisi, F. (2012). "Litigation And Legal Evolution: Does Procedure Matter?" Public Choice, 152, 181-201.

Parisi, F. (2002). "Rent-Seeking Through Litigation: Adversarial And Inquisitorial Systems Compared." International Review of Law and Economics, 22, 193-216.

Parisi, F. and Luppi, B. (2015). "Litigation as rent-seeking." In R. Congleton and A. Hillman (Eds.), A Companion to Rent Seeking: Theory and Practice. Chap. 17, 293-307.

Plott, C. (1987). "Legal fees: A comparison of the American and English rules." Journal of Law, Economics \& Organization, 3(2), 185-192.

Priest, G. and Klein, B. (1984). "The selection of disputes for litigation." Journal of Legal Studies, 13, 1-55.

Robson, A. and Skaperdas, S. (2008). "Costly enforcement of property rights and the coase theorem." Economic Theory, 36, 109-128.

Rosenberg, D. and Shavell, S. (1985). "A Model in Which Suits are Brought for their Nuisance Value." International Review of Law and Economics, 5, 3-13.

Shavell, S. (1982). "Suit, Settlement and Trial: A Theoretical Analysis Under Alternative Methods for the Allocation of Legal Costs." Journal of Legal Studies, 11, 55-81.

Skaderpas, S. (1996). "Contest Success Functions." Economic Theory, 7, 283-290.

Skaperdas, S. and Vaidya, S. (2012). "Persuasion as a contest." Economic Theory, $51,465-486$.

Snyder, E. and Hughes, J. (1990). "The English Rule for Allocating Legal Costs: Evidence Confronts Theory." Journal of Law, Economics and Organization, 6, 345-380.

Tullock, G. (1980). "Effcient rent seeking." in J. M. Buchanan, R. D. Tollison, and G. Tullock, eds., Toward a Theory of the Rent-Seeking Society, College Station: Texas A\&M. University Press, 97-112.

Waldfogel, J. (1995). "The Selection Hypothesis and the Relationship between Trial and Plaintiff Victory." Journal of Political Economy, 103, 229-260. 